\title{
Development of Spectrophotometric Method for the Determination of Atenolol in Normoten Drug
}

\author{
Isam Eldin Hussein Elgailani ${ }^{1}$, Tofeeg Haseen Alghamdi ${ }^{1}$ \\ ${ }^{1}$ Department of Chemistry, Faculty of Sciences and Arts at Baljurashi, Albaha University, Albaha, Saudi Arabia \\ Correspondence: Isam Eldin Hussein Elgailani, Department of Chemistry, Faculty of Sciences and Arts at Baljurashi, \\ Albaha University, Albaha P.O.Box 1988, Saudi Arabia. E-mail: gailani23@hotmail.com
}

Received: December 5, 2016

Accepted: December 28, 2016 Online Published: January 14, 2017

doi:10.5539/ijc.v9n1p58

URL: http://dx.doi.org/10.5539/ijc.v9n1p58

\begin{abstract}
This research aimed to develop inexpensive, safe, rapid, efficent spectrophotometric method for the assay of atenolol in some antihypertensive drugs namely Normoten in its pharmaceutical formulation. The studied method is depend on the reaction of the drug with phenol red in acidic medium, at $\mathrm{pH}$ 3.0. The analytical parameters have been investigated. The maximum absorbance was obtained at $429 \mathrm{~nm}$ and the molar absorptivity of $0.054 \mathrm{~L} \mathrm{~mol}^{-1} \mathrm{~cm}^{-1}$. Beer's law is linear in the concentration range of $0.5-100 \mu \mathrm{g} / \mathrm{mL}$ for atenolol in Normoten. The detection and quantification limits were found to be 0.038 and $0.113 \mu \mathrm{g} / \mathrm{mL}$ for the atenolol in Normoten respectively, and with a linear regression correlation coefficient of 0.997 . The recovery was found to be 98.94 to $100.31 \%$. The studied method is can be applied for the determination of atenolol (active ingredient) of the antihypertensive drugs in their pharmaceutical formulations.
\end{abstract}

Keywords: Normoten, antihypertensive drugs, atenolol, validation, UV-Visible spectrophotometer

\section{Introduction}

Normoten is categorized as cardiovascular system drugs which contains atenolol. Chemically atenolol known as 4-(2-hydroxy-3-[(1-methylethyl) amino] propoxy) benzeneacetamide as shown in Fig. 1 (O'Neil \& Budavari, 1989). Atenolol used for the treatment of hypertension, prevention of cardiovascular diseases (Gotardo, Sequinel, Pezza \& Pezza, 2008), treatment of antiangina (Hegde, Kumara Swamy, Sherigara \& Nandibewoor , 2008) and control of cardiac arrithymia (Hoffman, Hardman, Limbird, Gilman (eds), Goodman \& Goodman¥s, 1987).<smiles>CC(C)NCC(O)COc1ccc(CC(N)=O)cc1</smiles>

Figure 1. Chemical structure of atenolol

Several methods were used for the quantification of atenolol in bulk and pharmaceuticals. The United States Pharmacopeia uses HPLC method with UV detector for determination of atenolol in tablets (United States Pharmacopeia 2003), whereas the British Pharmacopoeia uses UV spectrophotometry (British Pharmacopoeia, 2001). Atenolol was determined by HPLC (Zarapkar, Kolte \& Rane, 1997; Radulovic, Zivanovic \& Velimirovic, 1991; Gong, 1989; Ceresole, Moyano, Pizzorno \& Segall, 2006; Rapado-Martinez, Garcia-Alvarez-Coque \&\& Villanueva-Camanas, 1997), high-performance thin-layer chromatographic (HPTLC) (Argekar \& Powar, 2000; Argekar \& Sawant, 1999), gas liquid chromatography (Sadana \& Ghogare, 1990; Rao, Avadhanulu, Giridhar, Pantulu \& Kokate, 1990), spectrofluorometry (Gajewska, Glass \& Kostelecki, 1992; Zhao, Yan \& Guo, 1994), atomic absorption spectrometry (El Ries, 1995), nuclear magnetic resonance spectrometry (Iorio, Mazzeo-Farina \& Doldo, 1987). Atenolol was determined spectrophotometrically with by using 2,4-dinitrophenol, 2,3-dichloro-5,6-dicyano-1,4-benzoquinone and 2,4,6 trinitrophenol (Prashanth \& Basavaiah, 2012), with hydroxylamine hydrochloride (Agrawal, Raman, Rajpu \& Menon, 1992), sodium nitroprusside (Bashir, Shah, Bangesh \& Riazullah, 2011), chloranil and propan-2-ol (Korany, Abdel-Hay, Galal \& Elsayed, 1984), permanganate in alkaline medium (Hiremath, Mulla \& Nandibewoor, 2005), metol and sulphanilic acid (Basavaiah, Chandrashekar \& Nagegowda, 2004), bromate-bromide mixture (Basavaiah, Chandrashekar \& Nagegowda, 2006), cerium(IV) sulphate (Basavaiah, Chandrashekar \& Nagegowda, 2003), choranilic acid (Agarwal, Singhal \& Prakash, 1998), 1,2-naphthoquinone-4-sulfonic (Ali \& Elbashir, 2013) and neutralization reaction with phenol red in acetone (Basavaiah, Chandrashekar, Somashekar, \& Ramakrishna, 2005). The objective of 
the current investigation is to validate cheap, safe, fast, precise and accurate spectrophotometric method for the analysis of some Antihypertensive drugs, using phenol red (PR) in ethanol as a chromogenic reagent. The method was depend on the complexation of the investigated drugs with phenol red (PR) to give coloured complex species measured at the visible region.

\section{Materials and Methods}

\subsection{Chemicals, Reagents and Apparatus}

Reagents and Chemicals of high grade of were used. Deionized water was used for solution preparation. The standard of Normoten was provided by (Jazeera Pharmaceutical Industries, Saudi Arabia. Normoten-50 (Atenolol) tablets was labeled to contain $50 \mathrm{mg}$ Atenolol per tablet. The analysis was carried out with a UV-VIS Spectrophotometer (SP-3000, Optima, Japan) with 1-cm quartz cells, Digital Water Bath (Daihan Labtech Co. Ltd., Indonesia) and pH-meter (Jenway Ltd., U.K.).

\subsection{Preparation of Phenol Red (PR) Solution}

An accurately weighed $1.0 \mathrm{~g}$ of phenol red were dissolved in $20.0 \mathrm{ml}$ ethyl alcohol, put into a $100 \mathrm{ml}$ volumetric flask and completed to the volume with deionized water and thoroughly mixed to prepare $(0.1-1.0 \% \mathrm{w} / \mathrm{v})$. The solution was kept in amber glass bottle to prevent it from light.

\subsection{Preparation of Buffer Solutions}

A preparation of buffer solutions were carried out by mixing acetic acid with sodium acetate solution, $\mathrm{Na}_{2} \mathrm{CO}_{3}$ solution with $\mathrm{NaHCO}_{3}$ solution and $\mathrm{NaH}_{2} \mathrm{PO}_{4}$ solution with $\mathrm{NaOH}$ solution to obtain $\mathrm{pH}$ of range 3.0- 11.0.

\subsection{Preparation of Stock Solutions of Normoten $(1000 \mu \mathrm{g} / \mathrm{mL})$}

An exactly $0.1 \mathrm{~g}$ of the drug was dissolved in methanol, put into $100 \mathrm{~mL}$ volumetric flask and completed to the volume with methanol and thoroughly mixed to obtain a solution of $1000 \mu \mathrm{g} / \mathrm{mL}$. The stock solution of Normoten (Atenolol) was further diluted to get solutions of $0.5-120 \mu \mathrm{g} / \mathrm{mL}$.

\subsection{Preparation of Sample Solutions of Normoten}

The contents of each of 3 tablets for the Normoten drug were ground and homogenized. An exact quantity equivalent to weight stated for each of the drug (Normoten $50 \mathrm{mg}$ ) was dissolved in methanol and transferred to a $25 \mathrm{~mL}$ volumetric flask, and then completed to the volume with the same solvent. Suitable dilutions of this solution with methanol were made for the analysis.

\subsection{Procedure for the Analysis Using Phenol Red as a Chromogenic Reagent}

About $2 \mathrm{~mL}$ of the prepared solutions of Normoten were put into $10 \mathrm{~mL}$ volumetric flask followed by addition of $2 \mathrm{ml}$ of $\mathrm{pH} 3.0$ and $1 \mathrm{~mL}$ of $0.80 \%(\mathrm{PR})$, the solutions were then heated to $40^{\circ} \mathrm{C}$ for $10.0 \mathrm{~min}$, the mixtures was diluted with methanol. The absorbance were read at $429 \mathrm{~nm}$ for the drug solution versus the blank.

\subsection{Account of the Molar Ratios}

The account of the molar ratios was determined by application of continuous variation method (Job, 928). Equal concentrations of $10.0 \mu \mathrm{g} / \mathrm{mL}$ for each of Normoten and (PR) were prepared. A volume of 10-mL of Normoten and (PR) were made up by the following ratios 0:10, 1:9, 2:8,3:7, 4:6, 5:5, 6:4, 7:3, 8:2, 9:1 and 10:0.

\section{Results and Discussion}

\subsection{Analysis of Absorption Spectra}

The maximum absorption spectrum of the reaction of Normoten with (PR) was obtained as shown in (Figures 2). The maximum absorption wavelength peak $\lambda \max$ at $340 \mathrm{~nm}$ for Normoten, and the $\lambda \max 460 \mathrm{~nm}$ for (PR), while the $\lambda \max$ for the drug with (PR) is $429 \mathrm{~nm}$ against the reagent blank. 


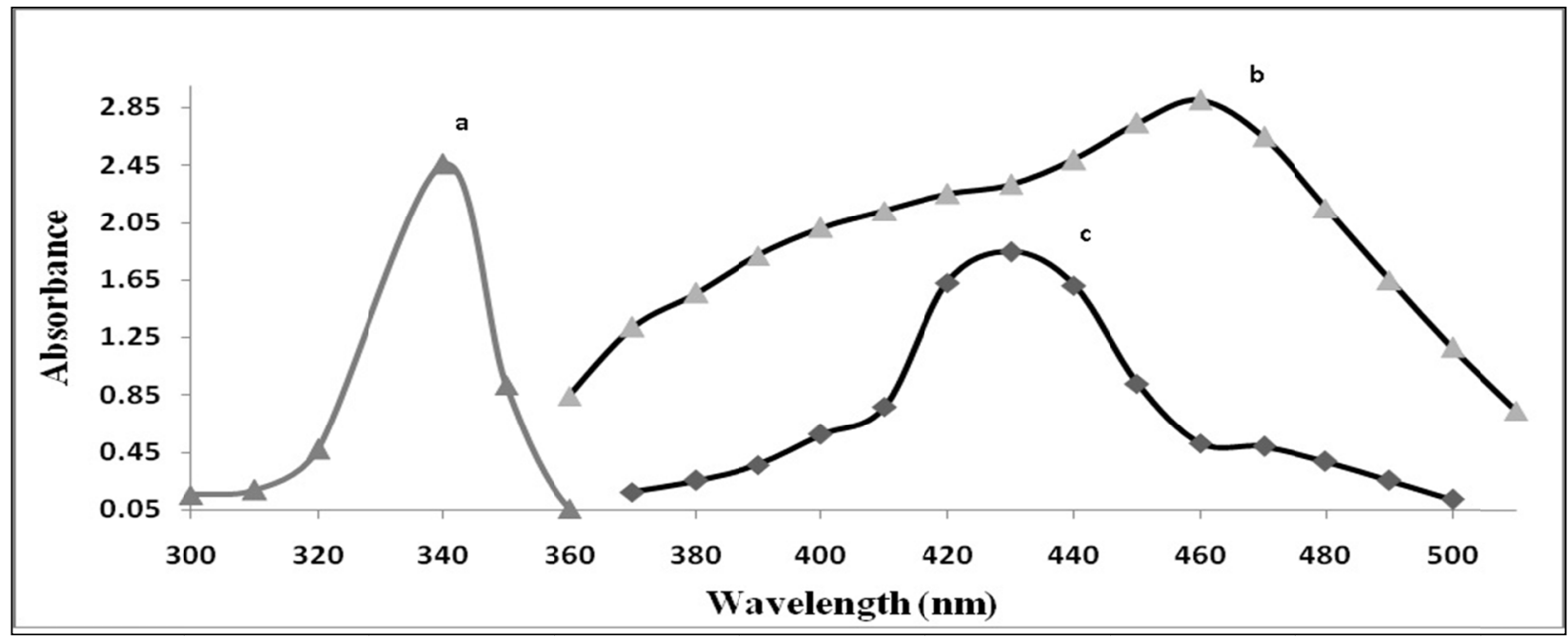

Figure 2. a- $\lambda \max$ of Normoten $(10 \mu \mathrm{g} / \mathrm{mL})$ against methanol, b- $\lambda \max$ of (PR) $(0.8 \%)$ against water, c- $\lambda \max$ of reaction of Normoten $(10 \mu \mathrm{g} / \mathrm{mL})$ with (PR) $(0.8 \%)$

\subsection{Optimization of the Reaction Variables}

The optimum conditions for the development of studied method were established by changing the amount of $\mathrm{pH}$, buffer volume, reagent (PR) concentration, temperature and standing time and the effect obtained on the absorbance was recorded, and they were found to be $3.0,2.0,0.80 \%, 40{ }^{\circ} \mathrm{C}$ and 10 minutes respectively as shown in (Fig 3).

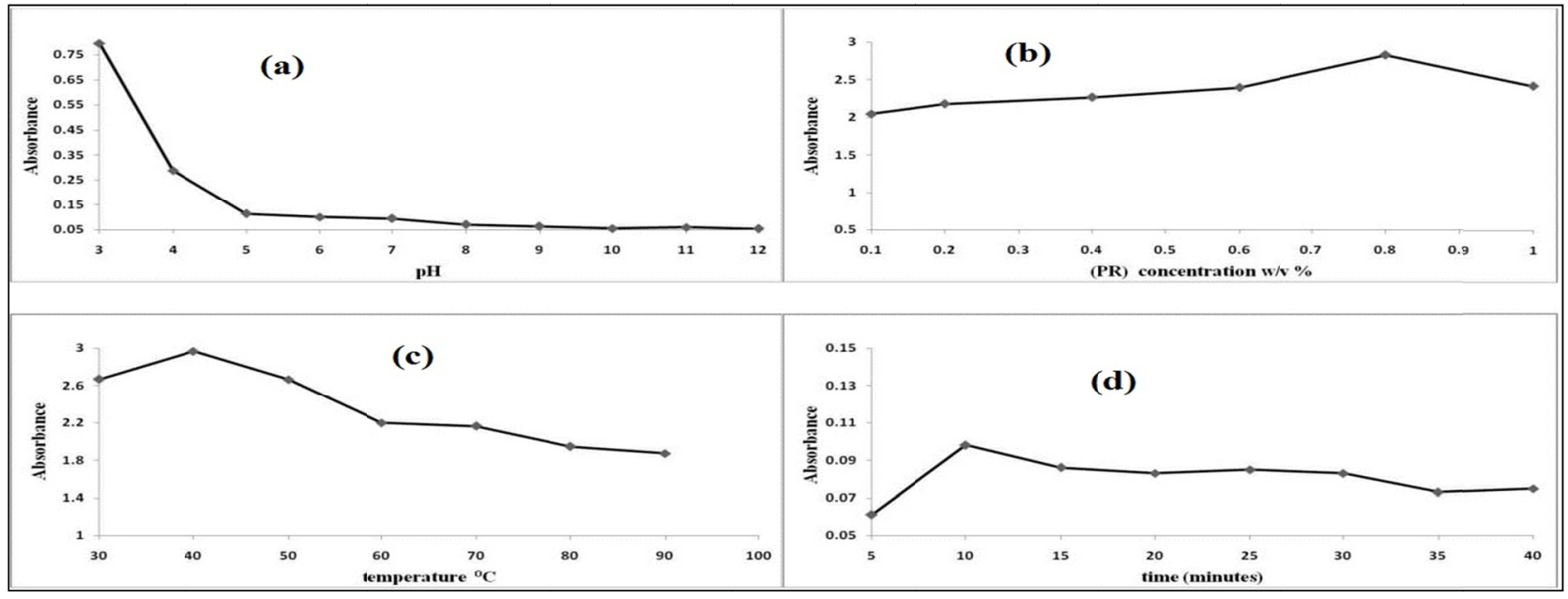

Figure 3. Effect of analytical parameters on the reaction of Normoten with (PR): (a) Effect of pH, (b) Effect of (PR) concentrations, (c) Effect of temperature, and (d) Effect of standing time

\subsection{Soichiometric Ratio of the Reaction}

The continuous variation of the method was carried out (Job, 928). Similar concentrations of Normoten drug solution and (PR) were prepared. Sets of $10 \mathrm{~mL}$ volumes of the solutions of drug and (PR) were carried out by the following ratios $(0: 10,1: 9,2: 8,3: 7,4: 6,5: 5,6: 4,7: 3,8: 2,9: 1,10: 0)$, The solution was further analyzed by the same procedure. The Job's graph was constructed which indicated that the ratio of (PR): Normoten drug reaction (Figure 4). 


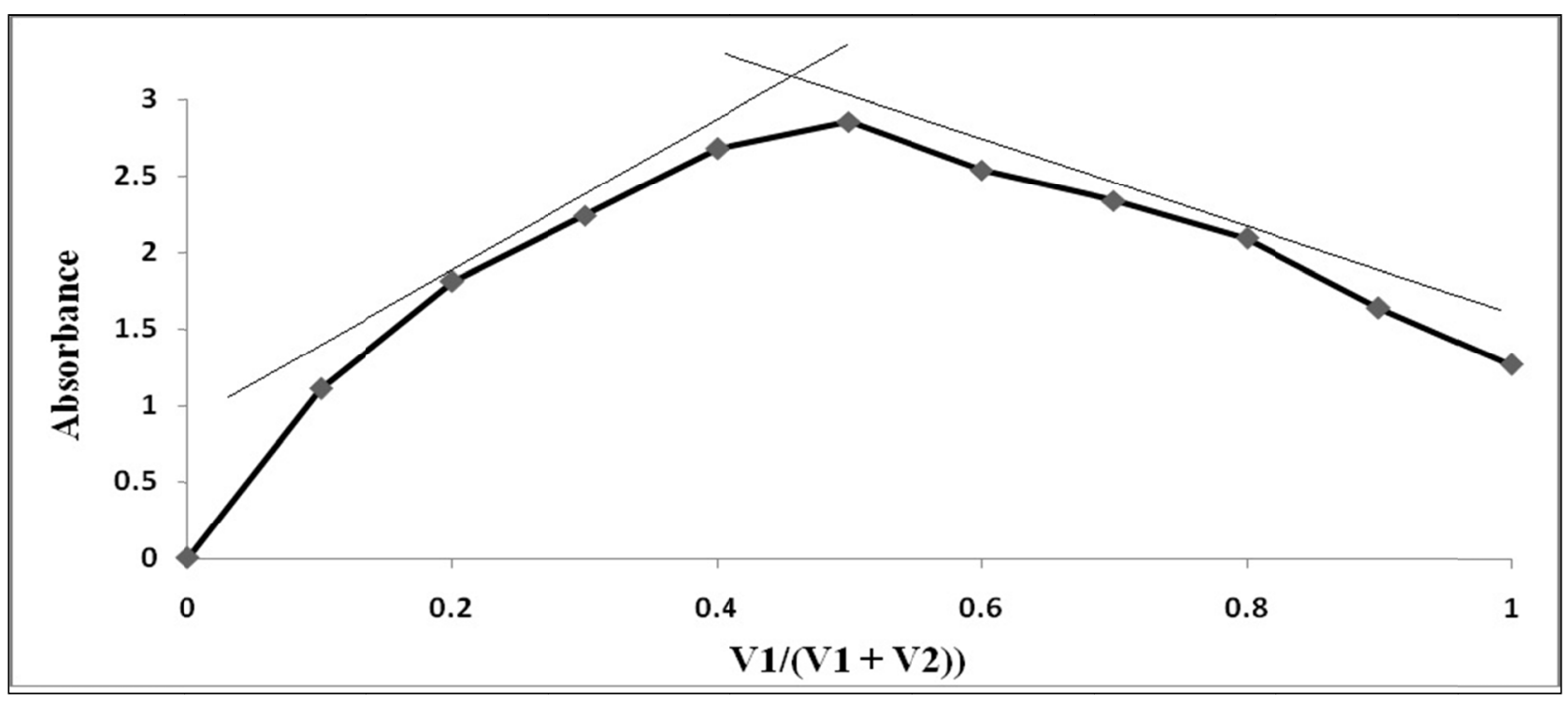

Figure 4. Stoichiometry by Job's method for (PR) with Normoten drug (V1:(PR) and V2 : drug sample)

\subsection{Method Validation}

Calibration curve for the analysis of studied drug samples (Normoten) and (PR) was setup by plotting the absorbance versus corresponding concentrations as shown in (Fig. 5). Linear graph with good $\mathrm{R}^{2}$ value was obtained in 0.5- 100 $\mu \mathrm{g} / \mathrm{mL}$. The detection limit (LOD) was determined from standard deviation of five determinations of blank $((\mathrm{n}=5, \mathrm{SD}$ $=0.0005)$ and the slope of the calibration graph.

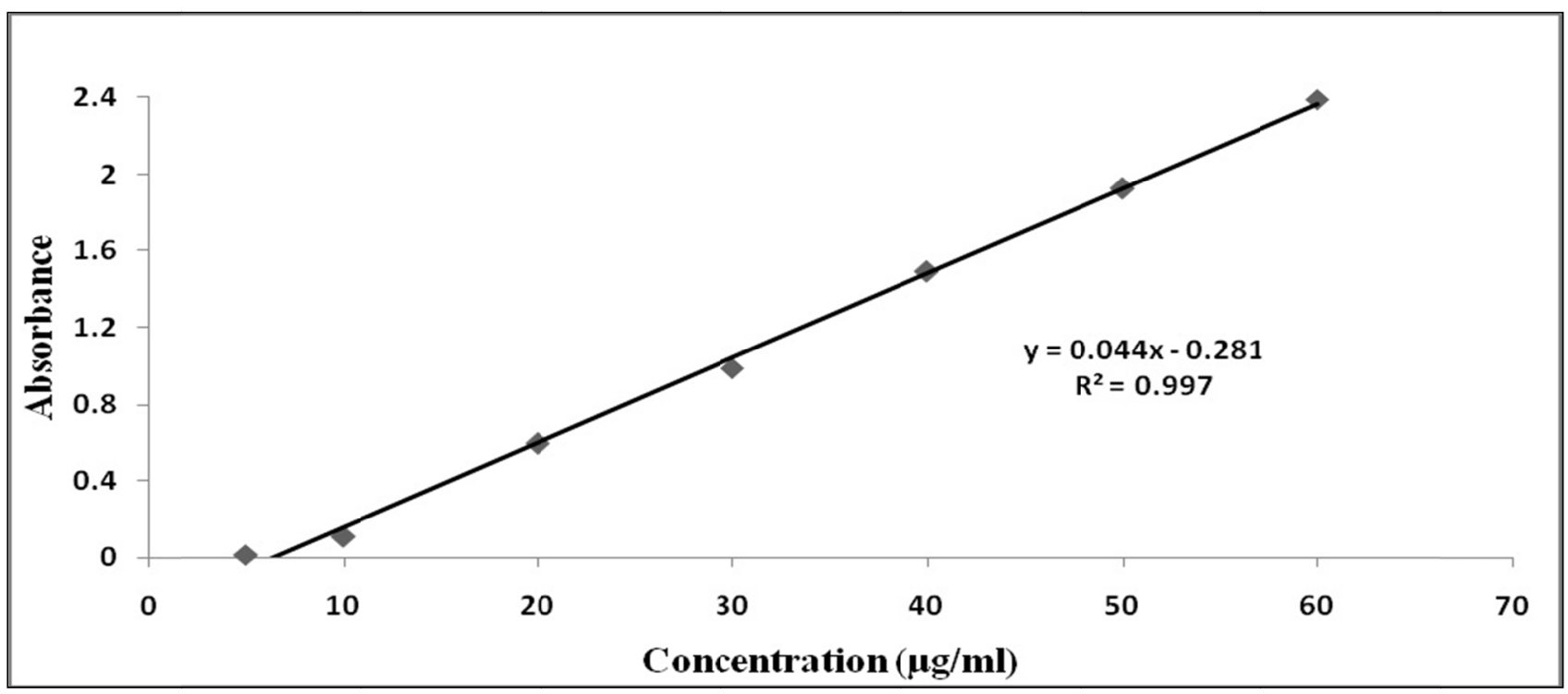

Figure 5. Calibration Curve of Normoten (Atenolol)

The equation of the linear line was found to be $\mathrm{Y}=0.044 \mathrm{X}+0.281$. The LOD and quantification limit (LOQ) were calculated as the guidelines of The International Conference of Harmonization for method validation (ICH Guideline, 2005). The analytical parameters were outlined in (Table 1). 
Table 1. Analytical parameters of the studied method

\begin{tabular}{cc}
\hline Parameter & Normoten drug sample and $(\mathrm{PR})$ \\
\hline$\lambda$ max $/ \mathrm{nm}$ & $429 \mathrm{~nm}$ \\
Beer's linearity $(\mu \mathrm{g} / \mathrm{mL})$ & $0.5-100$ \\
Molar absorptivity $\left(\mathrm{L} \mathrm{mol}^{-1} \mathrm{~cm}^{-1}\right)$ & 0.054 \\
$\mathrm{R}^{2}$ value & 0.997 \\
Regression equation $(\mathrm{Y})$ & $\mathrm{Y}=0.044 \mathrm{X}+0.281$ \\
Slope & 0.044 \\
Intercept & 0.281 \\
LOD $(\mu \mathrm{g} / \mathrm{mL})$ & 0.038 \\
LOQ $(\mu \mathrm{g} / \mathrm{mL})$ & 0.113 \\
\hline
\end{tabular}

Robustness is determined by changing with the small variations in the analytical parameters. The results revealed that the small changes did not influence the procedure as seen in (Table 2).

Table 2. Assay parameters of PR method on the suitability test parameters and sensitivity

\begin{tabular}{ccc}
\hline Condition & Normoten concentration $(10.0 \mu \mathrm{g} / \mathrm{mL})$ & Recovery $\% \pm \mathrm{RSD}$ \\
\hline $\mathrm{pH}$ & 2.80 & $100.68 \pm 0.23$ \\
& 3.20 & $99.39 \pm 0.35$ \\
$(\mathrm{PR})$ concentration & 0.78 & $99.55 \pm 0.46$ \\
$(\mathrm{w} / \mathrm{v} \%)$ & 0.82 & $100.68 \pm 0.46$ \\
Temperature $\left({ }^{\circ} \mathrm{C}\right)$ & 38 & $99.39 \pm 0.35$ \\
& 42 & $99.77 \pm 0.23$ \\
Reaction time (min.) & 8 & $101.14 \pm 0.23$ \\
\end{tabular}

- Each analysis was average of three readings $(n=3) .,{ }^{*}$ RSD is the relative standard deviation..

The accuracy and precision of the studied method were carried out by using three different concentrations of studied drug solutions. The percentages $f$ the relative error were found to be $0.227-0.645$, and the intraday and interday evaluations reveal that the method is of high accuracy and precision as shown in (Tables 3 and 4).

Table 3. Accuracy and precision

\begin{tabular}{cccccc}
\hline Sample & Taken & Found & \% Relative error & SD & \% RSD \\
\hline Normoten $(\mu \mathrm{g} / \mathrm{mL})$ & 10.00 & 10.045 & 0.450 & 0.046 & 0.458 \\
& 20.00 & 19.871 & 0.645 & 0.035 & 0.176 \\
& 30.00 & 30.068 & 0.227 & 0.045 & 0.150 \\
\hline
\end{tabular}

Values are mean of 3 readings. $(n=3)$.

Table 4. Evaluation of Interday and Intraday Accuracy

\begin{tabular}{ccccccccc}
\hline Added $(\mu \mathrm{g} / \mathrm{mL})$ & \multicolumn{4}{c}{ Interday $(\mathrm{n}=3)$} & \multicolumn{5}{c}{ Intraday $(\mathrm{n}=3)$} \\
\cline { 2 - 8 } 10 & Found & Recovery $\%$ & $\pm \mathrm{SD}$ & \%RSD & Found & Recovery \% & \pm SD & $\%$ RSD \\
20 & 9.955 & 99.55 & 0.023 & 0.231 & 9.932 & 99.32 & 0.046 & 0.463 \\
30 & 20.098 & 100.49 & 0.035 & 0.174 & 19.939 & 99.70 & 0.035 & 0.176 \\
& 30.091 & 100.30 & 0.068 & 0.226 & 30.060 & 100.20 & 0.056 & 0.182 \\
\hline
\end{tabular}

- Each analysis was average of three readings $(n=3)$.

Three different concentrations were added to a fixed amount of the prepared drug sample, standard Normoten, and the total was analyzed by the studied method. Each analysis was carried out three times. The recoveries were found to be in the range of 98.94 to $100.31 \%$ for the drug sample as shown in (Table 5).

Table 5 . The recovery

\begin{tabular}{ccccc}
\hline sample & $\begin{array}{c}\text { Normoten } \\
(\mu \mathrm{g} / \mathrm{mL})\end{array}$ & $\begin{array}{c}\text { Standard Normoten Added } \\
(\mu \mathrm{g} / \mathrm{mL})\end{array}$ & $\begin{array}{c}\text { Found } \\
(\mu \mathrm{g} / \mathrm{mL})\end{array}$ & $\begin{array}{c}\text { \% Recovery } \pm \\
\text { RSD }\end{array}$ \\
\hline Normoten & 10.0 & 5.0 & 14.841 & $98.94 \pm 0.31$ \\
$(\mu \mathrm{g} / \mathrm{mL})$ & 10.0 & 10.0 & 20.061 & $100.31 \pm 0.17$ \\
& 10.0 & 20.0 & 29.818 & $99.52 \pm 0.16$ \\
\hline
\end{tabular}

- Each analysis was average of three readings $(n=3)$.

It is obvious from the findings gained that the investigated method was of good analysis with respect of the analysis of atenolol in the antihypertensive drugs. Thus the sample of the drug (Normoten) was subjected to the analysis of its atenolol content by the proposed method and the percentage of recovery was found to be $99.50 \pm 0.05$ as (Percentage \pm $\mathrm{SD}$, and $\mathrm{n}=3$ ).

\section{Conclusions}

The current investigation showed the reproducible findings of phenol red (PR) reagent in the validation of simple, 
precise, accurate and fast spectrophotometric analysis for atenolol in antihypertensive drugs namely Normoten in its dosage forms. The investigated method is preferable to the past research spectrophotometric method for evaluation of Normoten as it is very simple. Moreover, the chemicals and reagents used in the analysis are cheap and available. Beside that the investigated method compromise an easy analysis of chromogenized species and no extraction processes was carried out. The studied method can be applied for any antihypertensive drugs containing atenolol.

\section{Acknowledgements}

Special thanks to the Department of Chemistry, Faculty of Science and Arts at Baljurashi, Albaha University where this evaluation and investigation have been carried out, for laboratory facilities and valuable assistance in the use of various equipments.

\section{References}

Agarwal, S. P., Singhal, V., \& Prakash, A. (1998). Spectrophotometric determination of atenolol and timolol dosage forms via charge-transfer complexation. Indian Journal of Pharmaceutical Sciences, 60(1), 53-55.

Agrawal, Y. K., Raman, K., Rajpu, S., \& Menon, S. K. (1992). Spectrophotometric determination of atenolol via hydroxamic acid formation. Analytical Letters, 25(8), 1503-151. http://dx.doi.org/10.1080/00032719208017132

Ali, A. A. A., \& Elbashir, A. A. (2013). A new spectrophotometric method for the determination of cardiovascular drugs in dosage forms. American Academic \& Scholarly Research Journal, 5(1), 116- 121. www.aasrc.org/aasrj .

Argekar, A. P., \& Powar, S. G. (2000). Simultaneous determination of atenolol and amlodipine in tablets by high-performance thin-layer chromatography. Journal of Pharmaceutical and Biomedical Analysis, 21(6), 1137-1142. https://doi.org/10.1016/S0731-7085(99)00210-1

Argekar, A. P., \& Sawant, J. G. (1999). Simultaneous determination of atenolol and nitrendipine in pharmaceutical dosage forms by HPTLC. Journal of Liquid Chromatography and Related Technologies, 22(10), 1571-1578. https://doi.org/10.1081/JLC-100101752

Basavaiah, K., Chandrashekar, U., \& Nagegowda, P. (2003). Titrimetric and spectrophotometric determination of atenolol using cerium(IV) sulphate. Bulgarian Chemical Communications, 35(3), 174-182. http://eprints.uni-mysore.ac.in/id/eprint/10983

Basavaiah, K., Chandrashekar, U., \& Nagegowda, P. (2004). Determination of atenolol by spectrophotometry based on charge transfer complex formation reaction. Acta Ciencia Indica Chemistry, 30(1), 75-79. http://eprints.uni-mysore.ac.in/id/eprint/11116

Basavaiah, K., Chandrashekar, U., \& Nagegowda, P. (2006). Titrimetric, spectrophotometric and kinetic methods for the assay of atenolol using bromate-bromide and methyl orange. Journal of the Serbian Chemical Society, 71(5), 553-563. https://doi.org/10.2298/JSC0605553B

Basavaiah, K., Chandrashekar, U., Somashekar, B. C., \& Ramakrishna, V. (2005). Development and validation of neutralization reaction based on analytical methods for the assay of atenolol in pharmaceuticals. Proceedings of the National Academy of Sciences of India A, 75(4), 233-238. http://eprints.uni-mysore.ac.in/id/eprint/11287

Bashir, N., Shah, S. W. H., Bangesh, M., \& Riazullah, R. (2011). A novel spectrophotometric determination of atenolol using sodium nitroprusside. Journal of Scientific and Industrial Research, 70(1), 51-54. http://hdl.handle.net/123456789/10778

British Pharmacopoeia Londom (2001): The Stationer Office, v.2

Ceresole, R., Moyano, M. A., Pizzorno, M. T., \& Segall, A. I. (2006). Validated reversed-phase HPLC method for the determination of atenolol in the presence of its major degradation product. Journal of Liquid Chromatography and Related Technologies, 29(20), 3009-3019. https://doi.org/10.1080/10826070600983393

El Ries, M. A. (1995). Indirect atomic absorption spectrometric (AAS) determination of atenolol. Analytical Letters, 28(9), 1629-1639. https://doi.org/10.1080/00032719508002770

Gajewska, M., Glass, G., \& Kostelecki, J. (1992). Spectrofluorimetric determination of propranolol and atenolol. Acta Poloniae Pharmaceutica, 49(3), 1-4. https://www.ncbi.nlm.nih.gov/pubmed/16092403.

Gong, L. (1989). High-performance liquid-chromatographic determination of atenolol in compound tablets. Yaowu Fenxi Zazhi, 9, 175-176.

Gotardo, M. A., Sequinel, R., Pezza, L., \& Pezza, H. R. (2008). Determination of atenolol in pharmaceutical formulations by diffuse reflectance spectroscopy. Ecletica Quimico, 33(4), 7-12. https://doi.org/10.1590/S0100-46702008000400001 
Hegde, R. N., Kumara Swamy, B. E., Sherigara, B. S., \& Nandibewoor, S. T. (2008). Electro-oxidation of atenolol at a glassy carbon electrode. International Journal of Electrochemical Science, 3(3), 302-314. www.electrochemsci.org

Hiremath, G. C., Mulla, R. M., \& Nandibewoor, S. T. (2005). Kinetic methods of determination of atenolol in pure compound and in pharmaceutical formulations. Chemia Analityczna, 50(2), 449-455.

Hoffman, B. B., Hardman, J. G., Limbird, L. E., Gilman (eds), A. G., Goodman \& Goodman¥s. (1987). The Pharmacological Basis of Therapeutics, tenth ed., pp. 1011-1021, MacGraw-Hill, Rio de Janeiro.

ICH Guideline (2005). Validation of Analytical Procedures: Text and Methodology, Q2 (R1), London.

Iorio, M. A., Mazzeo-Farina, A., \& Doldo, A. (1987). Quantitative analysis of $\beta$-adrenergic blocking agents by NMR spectroscopy. J. Pharm. Biomed. Anal., 5, 1-10. https://doi.org/10.1016/0731-7085(87)80002-X

Job, P. (1928). Formation and stability of inorganic complexes in solution. Annali di Chimica Applicata, 9, 113-203.

Korany, M. A., Abdel-Hay, M. H., Galal, S. M., \& Elsayed, M. A. (1984). Colorimetric determination of some beta-adrenergic blocking drugs in tablets. J. Pharm. Belg., 40, 178-184.

O'Neil , M. J., \& Budavari, S. (1989). Merck Index: An Encyclopedia of Chemicals, Drugs, and Biologicals, 11th Edn., p.136, Merck \& Co., Inc., Whitehouse Station, New Jersey. http://trove.nla.gov.au/version/28400809

Prashanth, K. N., \& Basavaiah, K. (2012). Simple, sensitive and selective spectrophotometric methods for the determination of atenolol in pharmaceuticals through charge transfer complex formation reaction. Acta Poloniae Pharmaceutica - Drug Research, 69(2), 213-223.

Radulovic, D., Zivanovic, L. J., \& Velimirovic, G. (1991). High-performance liquid-chromatographic determination of atenolol in tablets. Analytical Letters, 24(10), 1813-1823. https://doi.org/10.1080/00032719108053014

Rao, G. R., Avadhanulu, A. B., Giridhar, R., Pantulu, A. R. R., \& Kokate, C. K. (1990). Estimation of atenolol and nifedipine in single and combined dosage forms by GLC. Eastern Pharmacist, 33(386), 113-115.

Rapado-Martinez, I., Garcia-Alvarez-Coque, M. C., \& Villanueva-Camanas, R. M. (1997). Liquid chromatographic procedure for the evaluation of $\beta$-blockers in pharmaceuticals using hybrid micellar mobile phases. Journal of Chromatography A, 765(2), 221-231. https://doi.org/10.1016/S0021-9673(96)00919-3

Sadana, G. S., \& Ghogare, A. B. (1990). Quantitative gas liquid chromatographic determination of atenolol in bulk drug and pharmaceutical preparations. Indian Drugs, 28(3), 142-145.

United States Pharmacopeia (2016): USP 39, NF, 34(2).

Zarapkar, S. S., Kolte, S. S., \& Rane, S. H. (1997). High performance liquid chromatographic determination of amlodipine and atenolol, simultaneously from pharmaceutical preparation. Indian Drugs, 34(6), 350-353.

Zhao, H. C., Yan, N. H., \& Guo, J. X. (1994). Rapid determination of atenolol in tablets by flow injection fluorimetry. Fenxi Shiyanshi, 13(5), 36-38.

\section{Copyrights}

Copyright for this article is retained by the author(s), with first publication rights granted to the journal.

This is an open-access article distributed under the terms and conditions of the Creative Commons Attribution license (http://creativecommons.org/licenses/by/4.0/). 